\title{
ACULTURAÇÃO DE ALEMÃES E JAPONESES NO BRASIL
}

(Trechos de uma conferência)

\author{
Egon Schaden \\ Professor da Universidade de São Paulo
}

\section{Alemães e teuto-brasileiros}

Assim como a aculturação das populações indígenas em estado de marginalidade solicita o nosso interêsse de um lado pelos resultados teóricos que o seu estudo promete e começa a surtir e de outro pela perspectiva de conseqüências práticas, também as pesquisas relativas às populações alienígenas trazidas da Europa e da Ásia, a partir do século passado, para incrementarem o desenvolvimento de nossa lavoura, se nos apresentam com essa duplicidade de aspectos.

Todavia, entre nós, o estudo sistemático da aculturação e assimilação dos imigrantes é, por sua vez, um campo apenas parcialmente explorado. Com referência aos colonos alemães e seus descendentes nos Estados do Sul, a situação se tornou bastante auspiciosa com os trabathos de Emílio Willems, publicados nos últimos 20 anos, de modo que já se conhecem pelo menos algumas das linhas fundamentais dos processos de integração sócio-cultural dêsses grupos na comunidade nacional mais ampla. Alguns estudos menores de outros autores abrem mais algumas perspectivas para a continuação e aprofundamento das pesquisas. Com referência aos japoneses não há por enquanto nenhum estudo de envergadura, mas apenas trabalhos parciais e levantamentos preliminares realizados para melhor situação dos problemas. Mas estamos pelo menos em condições de esboçar alguns dos aspectos mais característicos. Com os alunos do curso de especialização em Antropologia encaminhamos na Universidade de São Paulo uma investigação sobre a aculturação dos imigrantes nipônicos em território paulista, com focalização especial dos problemas de aculturação econômica, sistemas de cooperação, conflito de gerações, aculturação religiosa e aculturação lingüística. Os resultados não estão, por enquanto, suficientemente precisos e seguros para permitirem formulações por assim dizer definitivas. Tudo, porém, faz prever que depois se revelarão sobremodo instrutivos os confrontos entre a aculturação dos japoneses e a dos alemães, principalmente no tocante à divergência em que se manifestam os fenômenos sócio-psíquicos resultantes dos choques culturais.

Os trabalhos de Emílio Willems sôbre as populações teutas do Brasil tomarem caráter ora mais sociológico, ora mais antropológico, circunstância pela qual o autor conseguiu, como nenhum outro, esclare- 
cer as relações entre sociedade e cultura com referência a fenômenos de aculturação no ambiente brasileiro. É neste setor particular que se encontra, a nosso ver, a sua principal contribuição ao conhecimento antropológico do Brasil. Tentamos aqui uma síntese das principais conclusões a que chegou no decorrer de prolongados estudos, sôbre a base de pesquisas de campo e de material bibliográfico. Em boa parte, a nossa tarefa é facilitada pelo recurso a um sumário - excelente, aliás que o próprio autor redigiu para uma revista sociológica alemã. ${ }^{1}$

Como ponto de partida, Willems toma as condições ecológicas da colonização alemã no Brasil. Em cêrca de o:tenta anos, o país recebeu sòmente uns 200.000 imigrantes alemães, mas o movimento de autocolonização, bem intenso, veio garantir à etnia teuta maior importância na vida nacional. Se bem que não haja uniformidade na constituição dos núcleos rurais - uns, fundados logo no início, sem depois receberem novos contingentes; outros, formando-se de levas sucessivas; outros, enfim, de origem recente - pode-se apontar, como condição ecológica fundamental o isolamento das colônias, que retardou a aculturação. Fundaram-se os núcleos, em sua maioria, numa região situada entre - litoral, com economia de pesca e pequena lavoura, e o planalto latifundiário de economia pastoril. O regime principal das colônias pequena propriedade com economia familial - foi a causa principal da impermeabilidade destas. Não havendo lugar para trabalhadores rurais brasileiros, a estrutura social constituiu-se quase exclusivamente de elementos teutos, mais ou menos homogêneos do ponto de vista cultural. De outro lado, porém, a falta de artesãos nas zonas luso-brasileiras semi-urbanas atraiu para lá certo número de imigrantes, que se assimilaram em pouco tempo.

$\mathrm{Na}$ transformação das comunidades teuto-brasileiras, distinguem-se três processos importantes para a assimilação: a urbanização, a industrialização e a formação de classes sociais. A urbanização, que se inicia com pequenos núcleos em tôrno da igreja, da escola, da venda, de pontos essenciais para o tráfego, e a industrialização, conseqüência do incremento que as pequenas oficinas locais tomaram na primeira guerra mundial, transformaram a estrutura da sociedade teuto-brasileira e as relações desta com a sociedade luso-brasileira. As vilas teuto-brasileiras receberam funcionários públicos, médicos, operários e outros elementos luso-brasileiros, que aí vieram encontrar ocupação e meio de vida, estabelecendo-se contactos primários, estímulos para a aculturação e a miscigenação. Ampliando-se, além disso, o horizonte cultural dos teuto-brasileiros, pelos interêsses comerciais e outros, surge a tendência para a aprendizagem do idioma português, o conhecimento das leis do país e a vinculação com a vida nacional. A aculturação atende, destarte, a dois estímulos: além de ser facilitada pela intensificação dos 
contactos, é compensadora, prometendo vantagens econômicas, políticas e sociais.

Aos processos indicados liga-se a formação de classes sociais. Uma fase de reorganização, sobretudo sôbre base econômica, sucede à nivelação inicial dos imigrantes. A classe superior constitui-se de negociantes de genêros coloniais, que se tornam grandes comerciantes; de donos ie primitivos teares domésticos, que se tornam industriais; e de industrializadores de produtos coloniais, que passam a ser donos de emprêsas consideráveis. Simultâneamente forma-se a classe proletária pelo recrutamento de trabalhadores para a indústria. Pelo fato de serem de origens étnicas diversas a de se unirem por uma solidariedade de classe sobreposta às diferenciações culturais, os componentes do proletariado tendem para a aculturação rápida, que os eproxima da população dom:nante na vida política. Por seu turno, a classe média, mais rural e de limitadas possibilidades econômicas (não podendo, por exemplo, proporcionár instrução secundária aos filhos), revela maior resistência à aculturação, ligando-se mais às sociedades escolares locais e, em certos casos, à igreja protestante.

É interessante observar a atitude em face da aculturação e assimilação nas colônias teuto-brasileiras desde o f.m da última guerra. Elementos arvorados em líderes culturais germânicos, repudiando, embora, tôda ligação política com a terra dos antepassados, fizeram nascer um movimento de - poderia dizer-se - recuperação cultural, centralizado principalmente em tôrno do problema lingüístico, menos no sentido de consciente atitude anti-aculturativa do que no de uma solução de compromisso, através do bilingüísmo. Diante da dificuldade de obter a necessária repercussão nos antigos meios coloniais, onde as crianças freqüentam as escolas públicas, o movimento assumiu feições de organização estruturada, com imprensa própria e outros meios de propaganda. Por enquanto, não é possível prever os resultados, que merecerão depois o interêsse dos antropólogos. A idéia central é a de uma cultura própria (mais ou menos germânica) nas áreas de colonização, distinta da cultura luso-brasileira dominante no país, cultura essa, porém, que não excluiria a participação plena de seus portadores da existência política e administrativa da Nação. Como se trata de processos $\mathrm{em}$ andamento, não se dispõe ainda, para o seu estudo, da necessária perspectiva antropológica; enquadram-se, evidentemente, a título de episódio, no conjunto da marcha aculturativa e só como tais podem ser compreendidos. A pretensão de cnalisá-los em separado despí-los-ia de seu caráter dinâmico, essencial em todo fenômeno de aculturação. Assinale-se, por enquanto, apenas o esforço de se dissociar o aspecto cultural do político e de se defender uma posição de compromisso, na qual havèria - cidadão brasileiro portador cie cultura germânica, f gura em todo 
caso problemática a vários títulos numa nação que nasceu sob o signo da unidade cultural.

\section{Japoneses e nipo-brasileiros}

Em confronto com a aculturação dos alemães, a dos japoneses assume muito mais abertamente a situação de conflito pròpriamente cultural, de vez que se trata de configurações bem mais distanciadas entre si. Sem falar da distância racial que separa os colonos nipônicos da população nacional e que dificulta a miscigenação, fazendo recrudescer, ao contrário, as valorações etnocêntricas, o idioma, a religião, o sistema familial, as concepções políticas, os hábitos de hig:ene, a cozinha e uma infinidade de costumes são de tal modo díspares qu a aculturação exige uma prévia fase de desintegração cultural bem mais radical e profunda nos japoneses e nipo-brasileiros do que em imigrantes de proveniência européia. Além disso, cumpre atender a importante fator histórico. A aculturação dos alemães se iniciou, embora lentamente, na primeira metade do século passado, tendo atravessado algumas de suas fases cruciais concomitantemente com a formação das primeiras gerações de teuto-brasileiros. No momento em que, motivado pela situação política internacional, o govêrno do país chamou a si a tarefa de incrementar o processo, já havia numerosos valores, padrões de comportamento, técnicas e instituiçc̃es integrados na cultura sui generis em elaboração. Recrudescendo embora, em virtude de condições políticas, o conflito cultural não chegou mais a um ponto em que originasse inteiro desequilíbrio $d_{e}$ instituições. Bem diversa é a situação dos japoneses. Iniciada pouco antes da primeira guerra mundial, a imigração era recente demais para que pudesse ter dado origem a gerações intermediárias de nipo-brasileiros que servissem, por assim dizer, de para-choque entre culturas antagônicas. A substituição de valores - políticos, religiosos, familiais etc. - se dá em cheio entre a geração dos que imigraram e a primeira dos que nasceram aqui. Talvez se deva a issu - grande número de personalidades neuróticas, a insegurança de atitudes e o freqüente recurso a soluções extremas a que se assiste nos grupos japoneses de São Paulo. A elevada freqüência de homicídios, suicídios, movimentos místico-políticos e manifestações congêneres mereceriam. acurado exame antropológico a êste respeito.

De qualquer forma, a rapidez com que o choque cultural entre japoneses e brasileiros assume feições de conflito, não requerendo, em geral, o espaço de uma geração, nos parece o motivo principal do fato de não se constituir aqui uma "cultura nipo-brasileira", ao contrário do que Emílio Willems julgou poder mostrar com referência a uma "cultura teuto-brasileira". Também a realidade desta não será reconhecida, sem mais discussão, pelos estudiosos do assunto, porquanto talvez não haja bastante uniformidade, nem suficiente estabilidade de padrões nas 
regiões coloniais do Paraná, de Santa Catarina e do Rio Grande do Sul para que se possa usar o têrmo. Com menos razão, porém, se há de falar em "cultura nipo-brasileira". Tal seria possível se a aculturação, nas colônias japonesas, se desenvolvesse de forma que, após uma fase de nivelamento cultural e social de cada núcleo, houvesse tempo e condições propícias para uma rediferenciação sôbre a base de uma estratificação social no interior dos próprios núcleos. Foi o que se deu com os alemães. Ėstes - e seus descendentes - antes de volverem as suas atenções para a cultura nacional, luso-brasileira, como veículo de ascenção social, puderam diferenciar-se em suas próprias colônias, através da formação de classes intra-étnicas. Sòmente mais tarde a população teuto-brasileira haveria de ocupar de algum modo o lugar de classe média na estrutura social do Brasil meridional.

Os japoneses e seus descendentes, por seu turno, não encaram a possibilidade de uma solução, por assim dizer, de compromisso. Ou se apegam ferrenhamente à cultura tradicional, ou a renegam de maneira cabal; na maioria dos casos são as atitudes de duas gerações sucessivas, a dos que vieram do Japão e a dos que nasceram aqui, o que não raro, como é fácil prever, acarreta fenômenos de desorganização familial.

A luta por um status social mais elevado não se desenvolve em geral no seio da comunidade colonial japonesa. Na medida em que existe, a diferenciação, especialmente sôbre base econômica, não chega a caracterizar os núcleos coloniais como sociedades nitidamente estratificadas. A ascenção na escala social se dá por meio de competição com a população nacional, luso-brasileira e urbana. O japonês abandona então a colônia e as atividades da lavoura, migrando para a cidade, onde umas tantas atividades técnicas ou comerciais the proporcionam um meio de integrar-se na sociedade local e de nela competir com elementos que não são de sua etnia. Mas esta migração é também a mola principal para incentivar processos aculturativos e assimilatórios.

Sobretudo a impossibilidade de fundarem no Brasil estabelecimentos de ensino secundário segundo seus padrões tradicionais é de importância para a aculturação e assimilação dos elementos nipônicos. Velho traço da cultura japonesa, a valorização do estudo e do saber livresco e a preocupação com a instrução dos filhos fazem que o colono japonês venha espontaneamente aproximar-se da cultura nacional. enviando os filhos às escolas normais e ginásios que fornecem dipiona cficial e abrem o caminho para os institutos de ensino superior, a que - japonês devota o mais profundo respeito. A aculturação dos japoneses é, assim, um problema de uma ou duas gerações; incrementa-a a competição por um "status" na sociedade nacional, competição em que - nipão recorre ainda a valores de sua cultura tradicional e que não se resumem, mas encontram uma de suas mais significativas expressões no aprêço que à escola e ao estudo livresco dispensa a trad ção japonesa. 
Enquanto permanece no meio rural, o japonês tem como maior barreira à aculturação o etnocentrismo que assume e nutre em face das populações brasileiras com que entra em contacto. Trata-se geralmente de caboclos que vivem segundo padrão econômico bem inferior ao do colono japonês. E quando se estabelecem relações entre as duas etnias, - japonês é que aceita trabalhadores rurais caboclos, o que, por sua vez, tende a acentuar as atitudes etnocêntricas.

Difícil é que, entre outras coisas, se incremente, em tal situação, o número de casamentos mistos, indispensáveis à assimilação, i. é, à absorção dos elementos nipônicos pela socidedade nacional. Ademais, tanto a estrutura da família patriarcal japonesa, quanto a relutância dos brasileiros em aceitarem cônjuge de origem japonesa são obstáculos não menos poderosos nesse sent:do. Um inquérito realizado por Willems entre alunas brasileiras de escolas normais de São Paulo mostrou que sòmente $6 \%$ das interrogadas admitia a possibilidade de ter um japonês como membro de família.

Enfim, a aculturação dos alemães e a dos japoneses, em que pese o número de linhas paralelas de seu desenvolvimento, toma feições características entre uns e outros em virtude de situações histórico-ecológicas especiais, que possibilitaram aos alemães a formação, não talvez de uma cultura híbr da, mas de combinações culturais várias como outras tantas soluções transitórias, elaboradas e sedimentadas durante mais de um século, e que, por outro lado, levaram o japonês a decisc̃es muito mais rápidas, mais incisivas e mesmo radicais. Em um e outro caso, porém, a integração do imigrante de seus descendente's na comunidade nacional brasileira se processa através da luta por um status nessa comunidade sendo decisivo o fato de a língua portuguêsa e muitos elementos culturais brasileiros assumirem a função de fatôres de distinção social. E através da ascenção na escala social se prepara, por sua vez, o terreno para número maior de casamentos mistos. A intensidade dos conflitos inter-étnicos que acompanham a aculturação e a assimilação, de um lado, e a absorção biológica, do outro, é antes de mais nada, decorrência do ritmo em que se desenvolvem, e no qual interferem fatôres históricos modificados pelas situações ecológicas das colônias. Daí a necessidade de se intensificarem as pesquisas pormenorizadas dos núcleos de imigrantes, a fim de que a comparação dos resultados particulares possa pôr a descoberto fenômenos que, no estado atual dos nossos conhecimentos, só podemos indicar de modo sumário, mas que merecem a atenção e o estudo acurado dos antropólogos.

\section{NOTA}

1) Emílio Willems, "Zur sozialen Anpassung der Deutschen in Brasilien", Kölner Zeitschrift für Soziologie, 1. Jahrg., Heft 3, S. 64-71; Köln-Opladen, 1948-49. 